This item was submitted to Loughborough's Research Repository by the author.

Items in Figshare are protected by copyright, with all rights reserved, unless otherwise indicated.

\title{
Relative proportion of vigorous physical activity, total volume of moderate to vigorous activity, and body mass index in youth: the Millennium Cohort Study
}

\section{PLEASE CITE THE PUBLISHED VERSION}

https://doi.org/10.1038/s41366-018-0128-8

\section{PUBLISHER}

(C) Macmillan Publishers Limited

\section{VERSION}

AM (Accepted Manuscript)

\section{PUBLISHER STATEMENT}

This work is made available according to the conditions of the Creative Commons Attribution-NonCommercialNoDerivatives 4.0 International (CC BY-NC-ND 4.0) licence. Full details of this licence are available at: https://creativecommons.org/licenses/by-nc-nd/4.0/

\section{LICENCE}

CC BY-NC-ND 4.0

\section{REPOSITORY RECORD}

Hamer, Mark, and Emmanuel Stamatakis. 2019. "Relative Proportion of Vigorous Physical Activity, Total Volume of Moderate to Vigorous Activity, and Body Mass Index in Youth: The Millennium Cohort Study". figshare. https://hdl.handle.net/2134/33191. 
Relative proportion of vigorous physical activity, total volume of moderate to vigorous activity, and body mass index in youth: the Millennium Cohort Study

Mark Hamer ${ }^{1} *$ PhD, Emmanuel Stamatakis ${ }^{2,3}, \mathrm{PhD}$

${ }^{1}$ School of Sport, Exercise and Health Sciences, Loughborough University, Loughborough, $\mathrm{UK}$;

${ }^{2}$ Charles Perkins Centre Epidemiology Unit, University of Sydney, Sydney, Australia;

${ }^{3}$ Prevention Research Collaboration, School of Public Health, University of Sydney, Sydney, Australia.

*Corresponding author: Mark Hamer, PhD, School of Sport, Exercise \& Health Sciences, Loughborough University, Loughborough, Leics LE11 3TU. Phone: +44 1509 228473. Email: m.hamer@lboro.ac.uk

Short title: Physical activity and BMI

Abbreviations: body mass index (BMI); moderate to vigorous physical activity (MVPA)

Word count $=1,494$

Potential Conflicts of Interest: The authors have no conflicts of interest relevant to this article to disclose.

Funding: Hamer acknowledges support from the National Institute for Health Research (NIHR) Leicester Biomedical Research Centre, which is a partnership between University Hospitals of Leicester NHS Trust, Loughborough University and the University of Leicester. Stamatakis is funded by the National Health and Medical Research Council (NHMRC) through a Senior Research Fellowship. The funders had no role in the study design; in the collection, analysis and interpretation of data; in writing of the report; or in the decision to submit the paper for publication. 


\section{Abstract}

2 The present physical activity guidelines suggest that when the overall activity energy

3 expenditure is held constant, moderate and vigorous intensity activities (MVPA) provide

4 equivalent health benefits. We explored associations between vigorous physical activity on

5 body mass index whilst controlling for volume of MVPA. In a longitudinal study with 7 years

6 follow up ( $\mathrm{n}=4,770$; aged 7 yrs old at baseline), physical activity was measured objectively at

7 baseline. Body mass index (BMI) was measured at baseline and follow up. Vigorous activity

8 was expressed as the percentage of total MVPA. Participants in the highest vigorous activity

9 tertile at baseline were at lower odds (odds ratio=0.70; 95\% CI, 0.55, 0.88) of overweight

10 /obesity at follow up compared with those in the lowest vigorous activity tertile after

11 adjustment for total volume of MVPA, BMI at baseline, sex, ethnicity, and social status. The

12 results suggest vigorous activity, regardless of volume, is important in preventing excessive

13 weight gain in young people. 
Evidence on the association between physical activity and obesity in young people is inconsistent. ${ }^{1-3}$ In particular, past studies have not adequately teased apart the importance of physical activity intensity and volume. In adult populations, epidemiological studies that have examined the association between physical activity intensity and cardiovascular disease, while controlling for the volume of activity, have yielded mixed results. ${ }^{4-7}$ Recent work investigated associations between vigorous intensity physical activity and body mass index in children but did not account for total volume of activity. ${ }^{8,9}$ The aim, therefore, was to explore longitudinal associations between objectively assessed vigorous physical activity on body mass index whilst controlling for volume of moderate and vigorous intensity activities (MVPA) using a large representative cohort study of children.

Methods Millennium Cohort Study between September 2000 and January 2002. Eligible children were identified from child benefit records, a benefit covering nearly all families in the UK. ${ }^{10}$ The fourth wave of data collection (when participants were aged 7 years: between May 2008 and August 2009) was used as the baseline for the present study as this was the first occasion that delivered by post to consenting participants and programmed to capture data every 15 
consecutive days but removed for the duration of water-based activities. Devices were returned and downloaded using Actigraph software (Actigraph, Pensacola, Florida). Based on a previous calibration study, ${ }^{11}$ moderate intensity activity was defined as 2240 - 3840 cpm and vigorous $\geq 3841 \mathrm{cpm}$. Reliable accelerometer data were less likely to be acquired from children who were: male; overweight/obese; of white, mixed or 'other' ethnicity; living in disadvantaged areas; had less educated mothers and/or lone mothers. ${ }^{12}$

Trained interviewers measured height and weight at age 7 and age 14. Height was taken using a Leicester height measure stadiometer with a Frankfurt Plane card. Weight was measured using Tanita scales (BF-522W), to the nearest $0.1 \mathrm{~kg}$. For both measures the participant was required to wear light indoor clothing and asked to remove their shoes and socks, and items in their pockets. Body mass index was calculated using the formula [weight, $\left.\mathrm{Kg} /(\text { height, } \mathrm{m})^{2}\right]$. Covariates for the present analyses included parental social occupational group, that was categorised by order of socioeconomic status: managerial/professional (highest); intermediate; semi-skilled/manual; semi-routine/routine (lowest). Other covariates included ethnicity and the cohort member's sex.

Linear regression models were used to examine associations between the proportion of vigorous activity relative to total MVPA (as a continuous variable) with BMI. Models were adjusted for total volume of MVPA, parental social occupational group, ethnicity, and BMI at baseline. Since models were adjusted for BMI at baseline, results represent associations between baseline activity with change in BMI between time-points. We tested for interactions by sex but as none were observed we pooled together boys and girls, and adjusted for sex. We used weighted analyses based on the accelerometry sub-sample. ${ }^{13}$ All analyses were conducted using SPSS version 22 with statistical significance set at $\mathrm{p}<0.05$.

\section{Results}


Based on the inclusion criteria (at least 2 days with $\geq 10 \mathrm{~h}$ wear time), ${ }^{14} 6497$ (3176

boys) study members provided valid accelerometry data at baseline. After exclusion of those with missing covariate and follow-up data, the final analytic sample comprised 4,770 participants. At least five valid wear days were recorded in $77.4 \%$ of the sample. In boys 62.9\% met the physical activity guideline (60 min daily MVPA on average) whereas this was achieved in $36.5 \%$ of girls. Other characteristics were similar between boys and girls (Table 1). On average, BMI was $16.5 \pm 2.3 \mathrm{~kg} \cdot \mathrm{m}^{-2}$ at baseline (age 7) and $21.4 \pm 4.2 \mathrm{~kg} \cdot \mathrm{m}^{-2}$ at follow up (age 14).

We did not observe any association between total MVPA volume and BMI at follow up (adjusted B=0.003, 95\% CI, $-0.002,0.007$ ). However, there was an association between the proportion of vigorous activity and BMI (adjusted B $=-0.031,95 \%$ CI, $-0.044,-0.017$ ) that persisted after adjustment for total MVPA volume and other covariates including baseline BMI. We did not stipulate the wear period to include a weekend day as a minimum wear criterion, although $80.6 \%$ of the sample did provide weekend data. We re-ran the models excluding participants without weekend Actigraph data and the association between the proportion of vigorous activity and BMI was not materially changed (adjusted B= -0.025 , $95 \%$ CI, $-0.040,-0.010$ ). We additionally adjusted the models for season of measurement, and results were practically unchanged (adjusted $\mathrm{B}=-0.031,95 \% \mathrm{CI},-0.045,-0.017$ ). We ran models separately in children from different ethnic background since prior results from this cohort have indicated stronger associations with adiposity-related outcomes in south Asian children. ${ }^{15}$ In these analyses the association between the proportion of vigorous activity and BMI was evident in south Asian participants (adjusted B= $-0.081,95 \% \mathrm{CI},-0.13,-0.03$ ) but not white children (adjusted B= -0.003, 95\% CI, $-0.018,0.011$ ).

There was a moderate correlation ( $\mathrm{r}=0.50$ ) between the proportion of vigorous activity and total MVPA volume, thus we repeated the analyses after stratifying the sample into 
tertiles of MVPA volume. The association between the proportion of vigorous activity and BMI was evident in the middle (adjusted $\mathrm{B}=-0.056,95 \% \mathrm{CI},-0.080,-0.030$ ) and upper (adjusted $\mathrm{B}=-0.028,95 \% \mathrm{CI},-0.048,-0.007$ ), but not the lower MVPA tertiles (adjusted $\mathrm{B}=$ 0.005, 95\% CI, -0.031, 0.022), as displayed in Figure 1a. The association between the proportion of vigorous activity and BMI did not change with additional adjustment for sedentary time (adjusted $\mathrm{B}=-0.018,95 \% \mathrm{CI},-0.32,-0.003$ ), and there was no evidence of effect modification (Figure 1b).

Using International Obesity Task Force age and sex specific thresholds $23.8 \%$ of the sample were overweight or obese at follow up. Participants in the highest vigorous activity tertile at baseline were at lower odds (odds ratio $=0.70 ; 95 \% \mathrm{CI}, 0.55,0.88$ ) of overweight /obesity at follow up compared with those in the lowest vigorous activity tertile after adjusting for total volume of MVPA, sex, parental social occupational group, ethnicity, and BMI at baseline.

\section{Discussion}

We explored longitudinal associations between objectively assessed physical activity and body mass index in childhood. A novel aspect of our analyses was to examine the contribution of vigorous intensity activity whilst controlling for MVPA volume. Consistent with some previous work we did not find any association between total volume of MVPA and BMI. ${ }^{3}$ However, relative proportion of vigorous activity was inversely associated with BMI at follow up whilst holding MVPA volume constant. That the association was not observed in the lowest tertile of MVPA volume suggests that associations of vigorous intensity activity are, in part, co-dependent on volume. That is, there may be an absolute threshold of vigorous activity needed to see benefits (i.e., children in the lowest, middle and 
highest MVPA volume tertiles recorded on average 11, 18, and 31 mins/d vigorous activity, respectively).

Evidence on physical activity and obesity in children is mixed, ${ }^{1-3}$ largely because studies have been limited by methodological problems including cross sectional designs, lack of power, and imprecise measurements of activity ${ }^{8}$ and adiposity. In addition, studies have tended to combine moderate and vigorous intensities of activity together without attempting to tease apart the effects of volume over intensity. Nevertheless, previous work using gold standard objective assessments of activity and adiposity have also demonstrated the importance of vigorous intensity activity. ${ }^{9}$ Although BMI is an objective measure, it is not a direct measure of adiposity. Previous evidence suggests associations between physical activity and adiposity were considerably weaker when using BMI, by a factor of around four, compared to using estimates of fat mass from imaging. ${ }^{16}$ Nevertheless, BMI has greater clinical utility.

Experimental studies with outcomes such as metabolic syndrome, cardiorespiratory fitness, blood pressure and lipid profiles ${ }^{17-20}$ indicate that the benefits of one minute of vigorous activity outweigh those of two minutes of moderate activity. Inverse associations between vigorous activity and obesity found in this study may be partly driven by favorable adaptations to lipid metabolism and other biological pathways.

We were unable to include important covariates such as diet and sleep, thus cannot rule out the possibility of residual confounding. Our findings that suggested possible ethnic differences should be interpreted cautiously as the south Asian sub-sample was very small $(n=361)$. Indeed, our results are inconsistent with other recent data showing that associations between physical activity and skinfolds were not modified by ethnicity. ${ }^{21}$ The analytic sample used in this study was more socially advantaged although weightings were used to reduce 
possible selection bias. Although associations appeared small in magnitude they may have

144 clinical relevance if physical inactivity persists across the life course into adulthood.

145

In conclusion, the results show vigorous activity, regardless of MVPA volume, is

146 important in preventing excessive weight gain in adolescence. 


\section{Acknowledgements}

Authors' contributions: Hamer obtained funding, conceptualized and designed the study, performed analyses, drafted the initial manuscript, and approved the final manuscript as submitted. He is the manuscript's guarantor. Stamatakis conceptualized and designed the study, provided statistical input and critical revision of the manuscript, and approved the final manuscript as submitted. 
References

1. Molnar D, Livingstone B. Physical activity in relation to overweight and obesity in children and adolescents. Eur J Pediatr 2000;159(suppl 1):S45-55.

2. Wareham N. Physical activity and obesity prevention. Obes Rev 2007;8(suppl 1):10914.

3. García-Hermoso A, Saavedra JM, Ramírez-Vélez R, Ekelund U, Del Pozo-Cruz B. Reallocating sedentary time to moderate-to-vigorous physical activity but not to lightintensity physical activity is effective to reduce adiposity among youths: a systematic review and meta-analysis. Obes Rev. 2017 May 19. doi: 10.1111/obr.12552. [Epub ahead of print].

4. Lee IM, Paffenbarger RS. Associations of light, moderate, and vigorous intensity physical activity with longevity - The Harvard Alumni Health Study. Am J Epidemiol. 2000;151(3):293-299.

5. Tanasescu N, Leitzmann MF, Rimm EB, Willett WC, Stampfer MJ, Hu FB. Exercise type and intensity in relation to coronary heart disease in men. Jama-J Am Med Assoc. 2002;288(16):1994-2000.

6. Shiroma EJ, Sesso HD, Moorthy MV, Buring JE, Lee IM. Do moderate-intensity and vigorous-intensity physical activities reduce mortality rates to the same extent? Journal of the American Heart Association. 2014;3(5):e000802.

7. Gebel K, Ding D, Chey T, Stamatakis E, Brown W, Bauman A. Effect of moderate to vigorous physical activity on all-cause mortality in middle-aged and older Australians. JAMA Internal Medicine. 2015;175(6):970-977.

8. Braithwaite IE, Stewart AW, Hancox RJ, Murphy R, Wall CR, Beasley R, Mitchell EA; ISAAC Phase Three Study Group. Body mass index and vigorous physical activity in children and adolescents: an international cross-sectional study. Acta Paediatr. 2017;106(8):1323-1330.

9. Collings PJ, Westgate K, Väistö J, Wijndaele K, Atkin AJ, Haapala EA, Lintu N, Laitinen T, Ekelund U, Brage S, Lakka TA. Cross-Sectional Associations of Objectively-Measured Physical Activity and Sedentary Time with Body Composition and Cardiorespiratory Fitness in Mid-Childhood: The PANIC Study. Sports Med. 2017;47(4):769-780.

10. Plewis I. The Millennium Cohort Study: Technical report on sampling: Centre for Longitudinal Studies, Institute of Education, University of London, London;2007.

11. Pulsford RM, Cortina-Borja M, Rich C. Actigraph accelerometer-defined boundaries for sedentary behaviour and physical activity intensities in 7 year old children. PloS one. 2011;6(8):e21822.

12. Rich C, Cortina-Borja M, Dezateux C, et al. Predictors of non-response in a UK-wide cohort study of children's accelerometer-determined physical activity using postal methods. BMJ Open 2013;3:pii: e002290.

13. Aggio D, Smith L, Fisher A, Hamer M. Context-Specific Associations of Physical Activity and Sedentary Behavior With Cognition in Children. Am J Epidemiol. 2016 Jun 15;183(12):1075-82.

14. Rich C, Geraci M, Griffiths L. Quality Control Methods in Accelerometer Data Processing: Defining Minimum Wear Time. PloS one. 2013;8(6):e67206.

15. Griffiths LJ, Sera F, Cortina-Borja M, Law C, Ness A, Dezateux C. Objectively measured physical activity and sedentary time: cross-sectional and prospective associations with adiposity in the Millennium Cohort Study. BMJ Open. 2016; 6(4):e010366. 
16. Riddoch CJ, Leary SD, Ness AR, Blair SN, Deere K, Mattocks C, Griffiths A, Davey Smith G, Tilling K. Prospective associations between objective measures of physical activity and fat mass in 12-14 year old children: the Avon Longitudinal Study of Parents and Children (ALSPAC). BMJ 2009;339:b4544.

17. Hidalgo-Santamaria M, Fernandez-Montero A, Martinez-Gonzalez MA, et al. Exercise intensity and incidence of metabolic syndrome: the SUN Project. Am J Prev Med. 2017;52(4):e95-e101.

18. Laursen AH, Kristiansen OP, Marott JL, Schnohr P, Prescott E. Intensity versus duration of physical activity: implications for the metabolic syndrome. A prospective cohort study. BMJ Open. 2012;2(5).

19. Janssen I, Ross R. Vigorous intensity physical activity is related to the metabolic syndrome independent of the physical activity dose. Int J Epidemiol. 2012;41(4):1132-1140.

20. Powell KE, Paluch AE, Blair SN. Physical activity for health: What kind? How much? How intense? On top of what? Annu Rev Public Health. 2011;32:349-365.

21. Collings PJ, Brage S, Bingham DD, Costa S, West J, McEachan RRC, Wright J, Barber SE. Physical Activity, Sedentary Time, and Fatness in a Biethnic Sample of Young Children. Med Sci Sports Exerc. 2017;49(5):930-938. 
Table 1. Characteristics of the sample at baseline (age 7)

\begin{tabular}{|l|l|l|}
\hline & Boys (n=2,441) & Girls (n=2,329) \\
\hline Parental social status (\%) & & \\
Managerial/professional & 31.8 & 31.3 \\
Intermediate & 20.1 & 19.2 \\
Semi-skilled/manual & 13.6 & 13.4 \\
Semi-routine/routine & 34.5 & 36.1 \\
\hline Ethnicity (\%) & & \\
White & 82.3 & 82.9 \\
Mixed & 5.6 & 4.7 \\
South Asian & 7.6 & 7.5 \\
Black & 2.8 & 2.8 \\
Other & 1.8 & 2.0 \\
\hline Moderate PA (min/d) & $47.3 \pm 13.5$ & $38.3 \pm 11.5$ \\
\hline Vigorous PA (min/d) & $22.3 \pm 11.5$ & $17.7 \pm 9.5$ \\
\hline \% Vigorous in relation to & $30.5 \pm 7.8$ & $30.2 \pm 7.4$ \\
total MVPA volume & & $5.5 \pm 1.6$ \\
\hline Valid days of Actigraph wear & $5.7 \pm 1.6$ & $16.6 \pm 2.4$ \\
\hline Body mass index (kg.m $\left.{ }^{2}\right)$ & $16.5 \pm 2.4$ & \\
\hline
\end{tabular}


Figure legend

Figure 1. The association between proportion of vigorous activity and BMI at follow up stratified by tertile of MVPA volume (panel a) and sedentary (panel b). Data are marginal means ( \pm standard error bars) adjusted for, sex, parental social occupational group, ethnicity, and BMI at baseline. Black, grey, and hatched bars reflect $<27 \%, 27-33.5 \%$, and $\geq 33.5 \%$, respectively, of vigorous activity in relation to total MVPA volume. For the main analysis the exposure variable was treated continuously but here the data are presented by tertiles with marginal means for illustrative purposes only. 
Figure 1 (panel a)

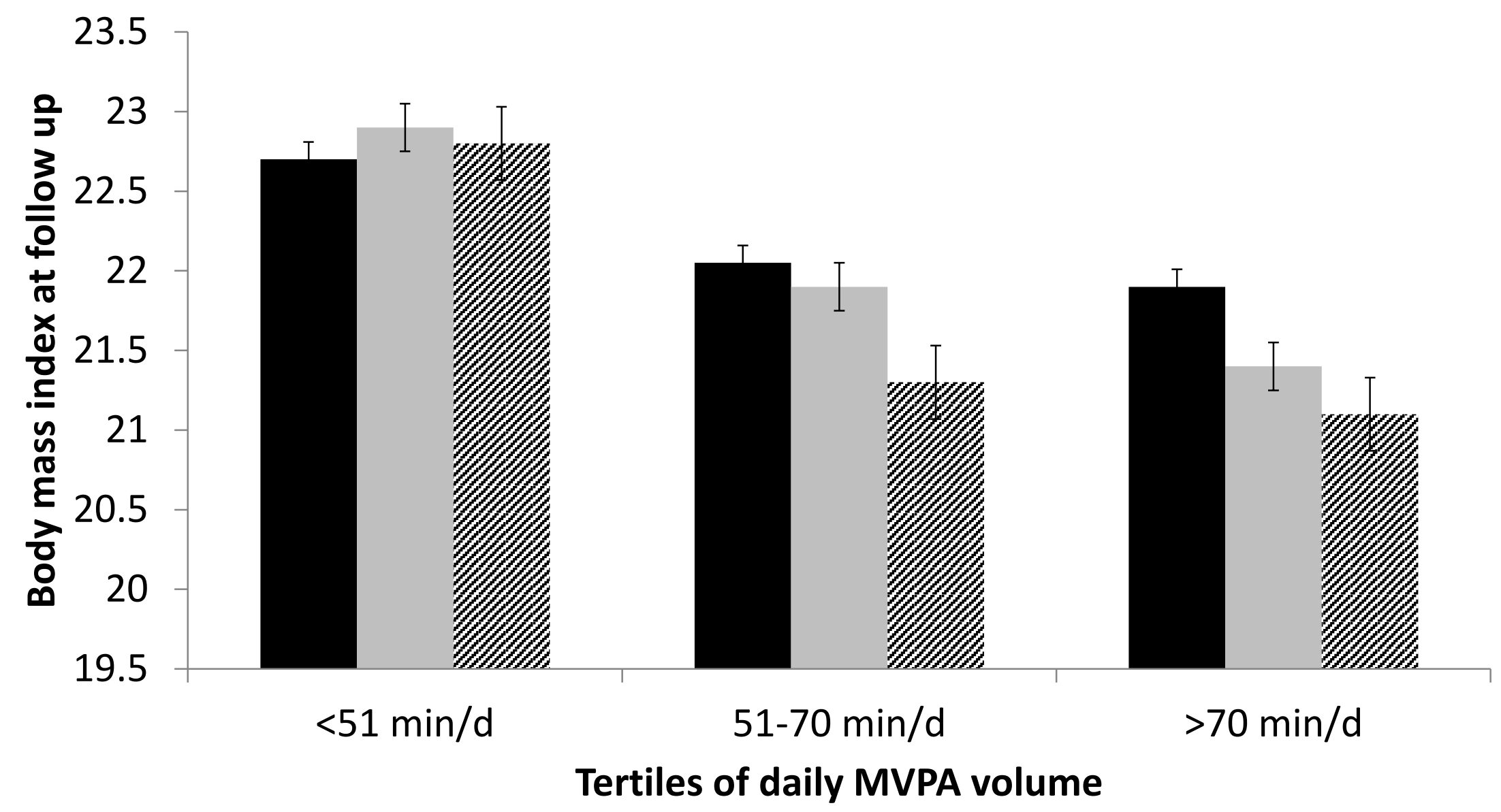


Figure 1 (panel b)

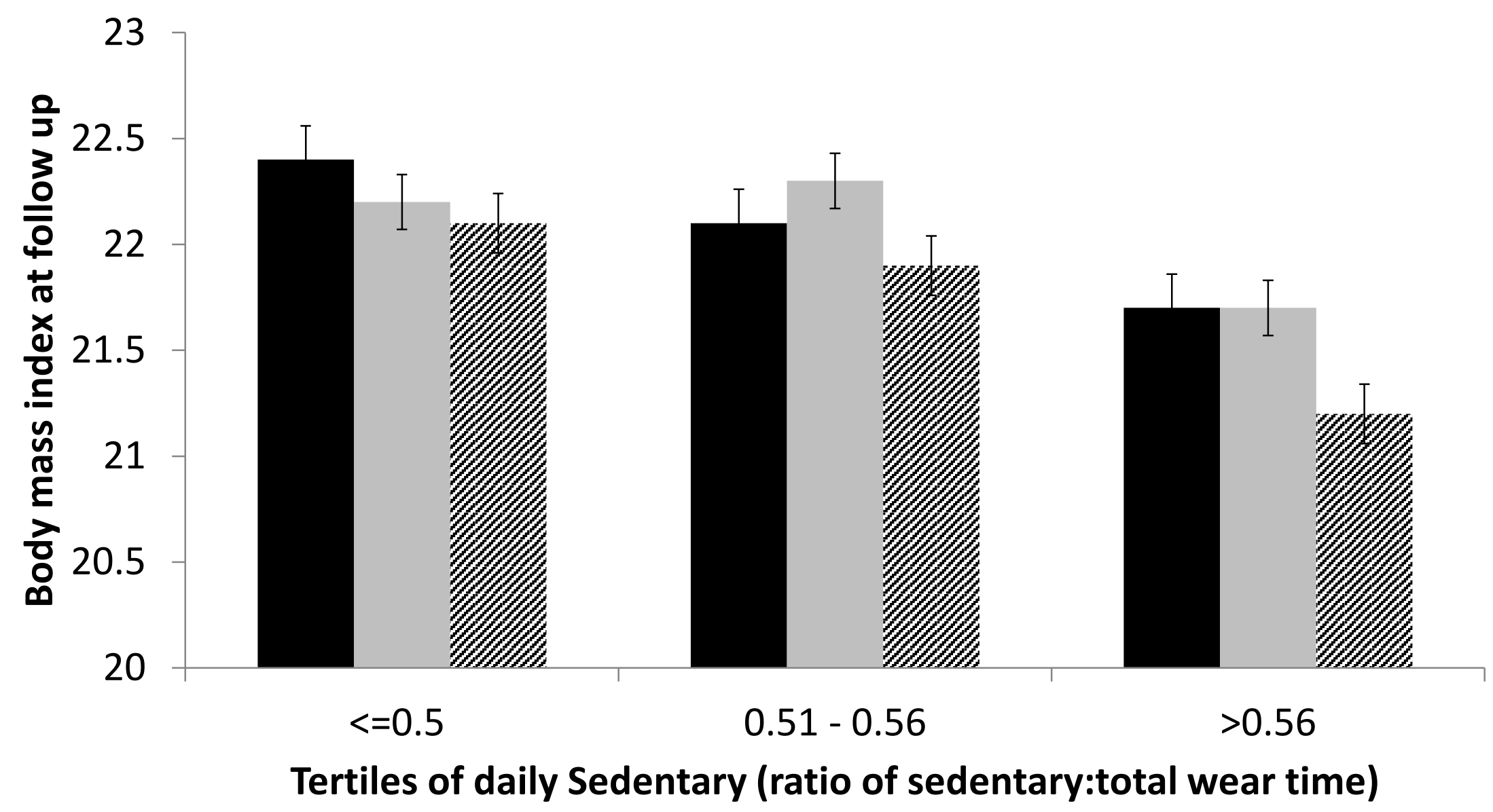

